\title{
Correlation between carotid intima-media roughness and cardiovascular risk factors
}

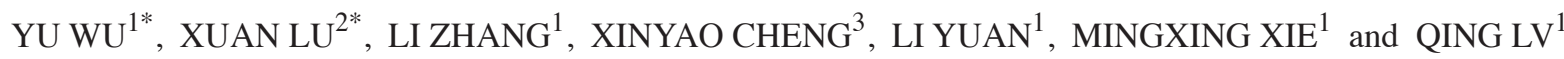 \\ ${ }^{1}$ Department of Ultrasound and ${ }^{2}$ Institute of Hematology, Union Hospital, Tongji Medical College, \\ Huazhong University of Science and Technology, Wuhan, Hubei 430022; ${ }^{3}$ Cardiovascular Division, \\ Zhongnan Hospital, Wuhan University, Wuhan, Hubei 430071, P.R. China
}

Received November 8, 2018; Accepted May 3, 2019

DOI: $10.3892 /$ etm.2019.7646

\begin{abstract}
Arterial intima-media roughness (IMR) may indicate an early manifestation of atherosclerosis. To date, few studies have been performed to quantitatively evaluate carotid IMR by ultrasonography (US). The aim of the present study was to analyze the effect of cardiovascular risk factors on carotid IMR. A total of 185 subjects were enrolled for US examination of carotid arteries. Carotid intima-media thickness (IMT) and IMR were measured in US images by a novel automatic software. According to the number of combined high-risk factors for coronary heart disease, subjects were assigned to four groups (risk groups 0, 1, 2 and $3+)$. IMR was lowest in risk group $0(32.9 \pm 2.7 \mu \mathrm{m})$, higher in risk group $1(64.5 \pm 6.9 \mu \mathrm{m} ; \mathrm{P}<0.01$ vs. risk group 0$)$ and highest in risk groups 2 and $3+(89.1 \pm 7.4$ and $92.0 \pm 6.7 \mu \mathrm{m}$, respectively; $\mathrm{P}<0.01$ vs. risk groups 0 and 1). According to a multivariate regression analysis, age, systolic blood pressure, smoking status and the triglyceride/high-density lipoprotein cholesterol ratio were significant predictors of IMR. There was a progressive increase in carotid artery plaque with increasing tertiles of IMR (4.9, 33.9 and $53.2 \%$ in tertiles 1, 2 and 3, respectively; $\mathrm{P}<0.05$ ). Compared with that of subjects in the lowest tertile of IMR, those in the highest tertile had a significantly elevated risk of the presence of plaque in the carotid tree (odds ratio $=10.61,95 \% \mathrm{CI}$ : 2.15-52.49, $\mathrm{P}=0.004)$. Quantification of carotid IMR from US images with this software is feasible, and carotid IMR, which may help estimate the extent of atherosclerosis, may
\end{abstract}

Correspondence to: Dr Qing Lv or Dr Mingxing Xie, Department of Ultrasound, Union Hospital, Tongji Medical College, Huazhong University of Science and Technology, 1277 Jiefang Avenue, Wuhan, Hubei 430022, P.R. China

E-mail: unionlq@outlook.com

E-mail: xiemx64@126.com

${ }^{*}$ Contributed equally

Key words: ultrasound, carotid intima-media roughness, carotid intima-media thickness, cardiovascular risk factors, atherosclerosis be used as a complementary factor to stratify patients with cardiovascular risk factors.

\section{Introduction}

Atherosclerosis is the primary cause of cerebrovascular and cardiovascular diseases, which are the leading causes of death among adults in China (1). Carotid intima-media thickness (IMT) measured by ultrasound (US) as a surrogate marker for atherosclerosis is widely used in basic and clinical research (2-4). The increase in the maximum IMT $\left(\mathrm{IMT}_{\text {Max }}\right.$ ) and mean IMT (IMT $\mathrm{IMean}_{\text {) }}$ is, however, only part of the information that reflects the atherosclerotic lesions in the artery $(5,6)$. At times, they also reflect the physiological aging processes (7).

Atherosclerosis is an inflammatory disease with a dynamic process (8). Local inflammation occurs in the formation of plaque $(9,10)$, which causes roughness of the IM layer. A prospective study has revealed that the surface granulation of the carotid arterial inner wall is closely associated with cardiovascular events (11). Carotid intima-media roughness (IMR) refers to a variation of IMT and measures the changes as granulations of the IM layer. Due to technical limitations, few studies have quantitatively evaluated the carotid IMR by using US. The purpose of the present study was to quantitatively measure the carotid IMR and investigate its clinical value in cardiovascular risk stratification.

\section{Materials and methods}

Study population. A total of 185 consecutive patients (mean age, $50.1 \pm 1.0$ years) who underwent carotid US examination at the United Hospital of Tongji Medical College of Huazhong University of Science and Technology (Wuhan, China) between November 2013 and January 2016 were enrolled in the present study. The exclusion criteria were as follows: i) Stroke; ii) acute myocardial infarction; iii) peripheral artery disease; iv) acute inflammatory diseases; v) malignant neoplasms. All participants were screened for risk factors of cardiovascular disease and were comprehensively evaluated, including review of medical history, physical examination and laboratory tests. 
Essential hypertension was diagnosed if the systolic blood pressure (BP) was $\geq 140 \mathrm{mmHg}$ and/or the diastolic BP was $\geq 90 \mathrm{mmHg}$ or if subjects were on BP-lowering drugs (12). Hyperlipidemia was diagnosed if the total cholesterol (TC) to high-density lipoprotein-cholesterol (HDL-C) ratio was $>5$ or the patient was undergoing treatment with lipid-lowering drugs (13). Diabetes was diagnosed if the fasting plasma glucose level was $\geq 126 \mathrm{mg} / \mathrm{dl}$ on at least two occasions or if subjects were undergoing treatment with anti-diabetic drugs (14). Obesity was diagnosed if the body mass index (BMI) was $\geq 28 \mathrm{~kg} / \mathrm{m}^{2}$ (15). The Framingham risk score (FRS) was used to estimate the 10 -year risk of coronary heart disease (CHD) events (16). The smoking status included past and present smoking. The FRS was calculated by points of risk factors: Age, total cholesterol level, HDL-C level, systolic BP and smoking status.

US examination. Carotid US was performed with a US machine (SSD- $\alpha 10$; Aloka) using a UST5412 probe with a transmission frequency of $5-13 \mathrm{MHz}$ by a researcher, who was blinded with regard to participant history. With subjects placed in the supine position in a quiet air-conditioned room $\left(22-24^{\circ} \mathrm{C}\right)$, the extracranial carotid arteries were visualized in the longitudinal and transverse planes. The entire length of the common carotid arteries (CCAs) and carotid bifurcations, including the internal carotid artery as far up as was possible to observe, was examined for the presence of atherosclerotic plaques. Plaque was defined as a focal structure encroaching into the arterial lumen by at least $0.5 \mathrm{~mm}$ or $50 \%$ of the surrounding IMT value exhibiting a plaque thickness of $>1.5 \mathrm{~mm}$ (17). The longitudinal scan images (acquired while keeping the beam parallel to the vessel wall) were stored on CD-R disks in DICOM format for off-line analysis. The left CCA within $1.5 \mathrm{~cm}$ of the bifurcation was visualized in the longitudinal plane by US.

IMT and IMR. Clear longitudinal scan images of the far wall at the T-wave end frame of the cine-loop recording were selected for analysis. Measurements were made with computer-assisted analysis software by using a previously validated snake model-based segmentation method to detect the IM boundaries automatically (18).

The IMT and IMR were measured at the far wall of the CCA and not at the near wall, as the measurement at the near wall has a larger angle between the US beam and the vessel wall, which affects the measurement results, and because far-wall measurements are considered to have a higher validity than near-wall measurements (19).

IMT was defined as the distance between the lumen-intima interface and the media-adventitia interface, as reported previously (20). A longitudinal region of interest was selected and the IM boundaries were demarcated. IMT measurement was performed along each vertical pixel line throughout the entire target vessel in the longitudinal section (Fig. 1). The $\mathrm{IMT}_{\text {Mean }} / \mathrm{IMT}_{\text {Max }}$ was obtained by calculating the average/max value of these data. IMR was obtained by calculating the standard deviation of these data.

Reproducibility of IMR. Intra- and interobserver variability of the measurement of IMR were evaluated through blinded repeated measurements of the same imaging data set of 30 subjects on two different occasions 2 weeks apart, with a single researcher for intraobserver variability and with two different researchers for interobserver variability.

Statistical analysis. Values are expressed as the mean \pm standard error of the mean or as percentages. Student's t-test and analysis of variance, with Fisher's least significant difference post-hoc test, were used to compare the mean values of the measured variables among the groups. The chi-square test was used for categorical data. Pearson correlation coefficients were assessed in univariate analyses comparing IMR and various parameters. Multivariate linear regression analysis was performed using standard least squares to assess the independent predictive value of the IMR; odds ratios (ORs) were calculated to determine the independent contribution of IMR to carotid atherosclerosis $($ absence $=0$, presence $=1$ ). The Bland-Altman test was used to assess variability in the method. The coefficient of variation was calculated as $\mathrm{SD}(\mathrm{x}-\mathrm{y}) / \mathrm{mean}(\mathrm{x}, \mathrm{y}) \mathrm{x} 100 \%$. SPSS statistical software version 13.0 for Windows (SPSS, Inc.) was used for analysis. $\mathrm{P}<0.05$ was considered to indicate statistical significance.

\section{Results}

Population characteristics. Table I presents the clinical and biochemical characteristics of the patients. Of the 185 subjects, $56(30.3 \%)$ had hypertension, $77(41.6 \%)$ had diabetes, 53 (28.6\%) had hyperlipidemia and 52 (28.1\%) were smokers. The prevalence of smokers was significantly higher in males than in females (chi-square $\mathrm{P}<0.01$ ), as was the BMI (t-test $\mathrm{P}<0.01)$.

Correlation between IMR, IMT and cardiovascular risk factors. A significant positive correlation was determined between IMR and FRS ( $\mathrm{r}=0.438$; $\mathrm{P}<0.001$; Fig. 2A). Patients were then categorized into three groups according to FRS tertiles (ranges of score: -7-5; 5-11; 11-20); the IMR and $\mathrm{IMT}_{\text {Mean }}$ increased progressively and significantly with increasing tertiles of CHD risk factor score (Fig. 2B).

A total of 40 subjects had no major CHD risk factors, 43 subjects had only one CHD risk factor, 53 subjects had two CHD risk factors and 49 subjects had three risk factors or more. Subjects with risk factors had significantly higher values of IMR and $\mathrm{IMT}_{\text {Mean }}$ than those without risk factors (Fig. 2C, Table II).

Pearson correlation analysis results are demonstrated in Table III. The IMR, similar to the IMT $_{\text {Mean }}$, was significantly correlated with several risk factors for CHD. Multiple regression analysis was performed with IMR and $\mathrm{IMT}_{\text {Mean }}$ as the dependent variables and with variables that met statistical significance in the univariate analysis of IMR and IMT $_{\text {Mean }}$. The analysis indicated that Age, SBP, smoking status and TC/HDL-C ratio were independently associated with IMR and $\mathrm{IMT}_{\text {Mean }}$.

Association between IMR and carotid atherosclerosis. The prevalence of carotid plaque in the whole study population was $30.8 \%$ (Table I) and increased progressively and significantly between risk 1 ( 1 risk factor) and risk 2 ( 2 risk factors) for 

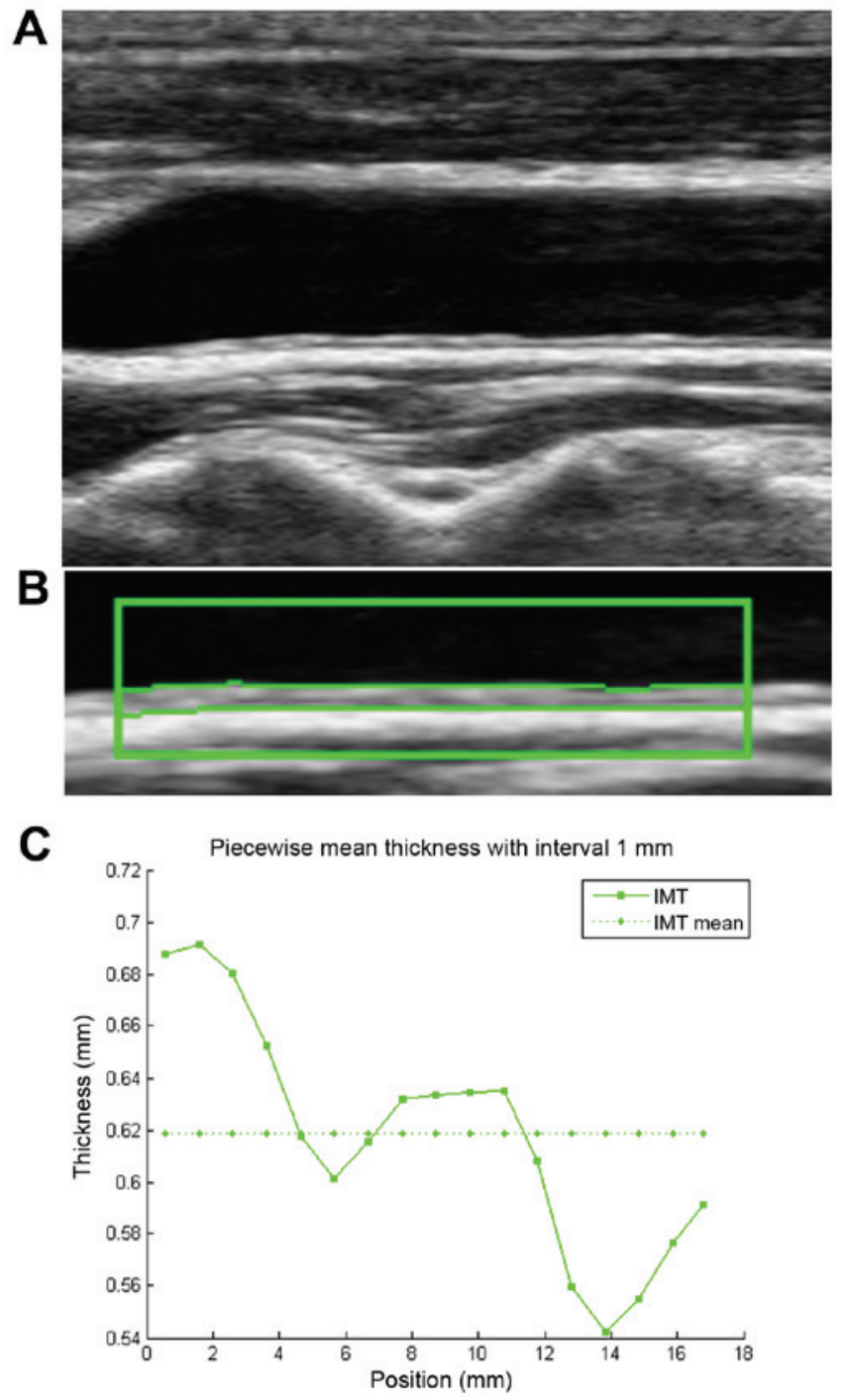

Figure 1. Carotid IMT and intima-media roughness measurements. (A) Ultrasound image of carotid longitudinal axis (depth $2.5 \mathrm{~cm}$ ) (B) On ultrasound images, the carotid intima-media boundary is delineated by software. (C) Curve of IMT in the region of interest. IMT, intima-media thickness.

CHD (chi-square test $\mathrm{P}<0.05$; Table II). The subjects were then stratified based on the presence of carotid plaque (absence $=0$, presence=1). IMR was significantly higher in subjects with carotid plaque than in subjects without carotid plaque (103.6 \pm 7.1 vs. $57.9 \pm 3.6 \mu \mathrm{m}$; $\mathrm{P}<0.001$; Fig. 2D).

In a further analysis, all subjects were divided into three groups according to IMR tertiles. There was a significant increase in the prevalence of carotid plaque across the tertiles of IMR $(4.9,33.9$ and $53.2 \%$ in tertiles 1,2 and 3 , respectively; $\mathrm{P}<0.05$; Table IV). Compared with those subjects in the lowest tertile of IMR, those in the intermediate and highest tertiles had a significantly elevated OR regarding the presence of plaque in the carotid tree (intermediate tertile, $\mathrm{OR}=9.90,95 \% \mathrm{CI}$ : 2.77-35.41, $\mathrm{P}<0.001$; highest tertile, $\mathrm{OR}=22.00,95 \% \mathrm{CI}: 6.22-77.81, \mathrm{P}<0.001$ ). Logistic regression adjusted for age, sex, smoking status, obesity, hypertension, diabetes mellitus and hyperlipidemia indicated that there were still significantly increased ORs for those subjects in the highest tertile compared with the lowest tertile $(\mathrm{OR}=10.61,95 \% \mathrm{CI}: 2.15-52.49, \mathrm{P}=0.004$; Table IV).

Coefficient of variation of repeated measurement. The measurements of IMR demonstrated an intra-observer variability with a coefficient variation of $6.8 \%$ and interobserver variability with a coefficient variation of $9.4 \%$. The Bland-Altman plots suggested that differences between the two measurements in inter-observer were similar throughout the range of IMR, with the difference between the two measurements in intra-observer also similar (Fig. 3).

\section{Discussion}

Atherosclerosis is the primary cause of vascular disease (1). The ability of non-invasive methods to detect atherosclerosis is a matter of clinical interest. Carotid IMT is a surrogate indicator of atherosclerosis for predicting cardiovascular and cerebrovascular outcomes (21). US represents a simple, non-invasive technique for the measurement of IMT, which is widely used to study the presence and progression of atherosclerosis (22-24). The increase in the $\mathrm{IMT}_{\text {Max }}$ and $\mathrm{IMT}_{\text {Mean }}$ is, however, only a part of the information that reflects the atherosclerotic lesions in the artery (4-6). IMR, describing the amount of variation of a set of IMTs, is expected to be able to quantify the irregularities of the IM layer. Certain studies have pointed out that besides IMT, a rough intimal surface is also a typical feature of atherosclerosis (13). Due to the limitation of measurement technology, research on IMR is rare. In the present study, computer-assisted analysis software was used to automatically track the IM layer, obtain the IMT value of each pixel in the region of interest and calculate its standard deviation to reflect the IMR. In a previous study by our group and in the present study, the Bland-Altman test demonstrated that measurement of the IMR was reproducible and was able to stably reflect the morphologic changes of the carotid IM (25).

Various risk factors influence IMT (26). In the present study, the IMR was also increased in association with several CHD risk factors, including age, hyperlipidemia, hypertension and cigarette smoking, and was significantly associated with FRS, which is a risk score and an index of cumulative cardiovascular risk commonly used for assessing the probability of heart attack or death from heart disease within 10 years (16). The results of Cheng et al (27) are similar to those of the present study where the presence of only one risk factor was associated with a significant increase in IMR and IMT. Furthermore, the IMR and IMT increased with the number of cardiovascular risk factors. It is worth noting that when the two risk factors are combined, only IMR is increased compared to the low-risk group (1 risk factor), whilst IMT displays no significant change. This indicates that the IMR is more sensitive to the influence of risk factors than the IMT. The reason may be that IMR is more sensitive to atherosclerosis than IMT. Atherosclerosis is an inflammatory disease with the characteristics of inconsistent lesion degree of vascular segments $(15,28)$. Local inflammation occurs during the formation of plaque (29), which leads to roughness of the IM layer. Therefore, IMR reflects atherosclerotic changes in the vascular wall. Although the IMT is highly associated with atherosclerosis, increasing IMT may not always be due 
Table I. Characteristics of all subjects.

\begin{tabular}{|c|c|c|c|c|}
\hline Parameter & Total $(\mathrm{n}=185)$ & Range & Males $(n=112)$ & Females $(n=73)$ \\
\hline Age (years) & $50.1 \pm 1.0$ & $19-87$ & $48.6 \pm 1.3$ & $52.3 \pm 1.4$ \\
\hline Smoking & $52(28.1)$ & & $52(46.4)$ & $0(0)^{\mathrm{a}}$ \\
\hline Hypertension & $56(30.3)$ & & $30(26.8)$ & $26(35.6)$ \\
\hline Diabetes & $77(41.6)$ & & $52(46.4)$ & $25(34.2)$ \\
\hline Hyperlipidemia & $53(28.6)$ & & $35(31.3)$ & $18(24.7)$ \\
\hline \multicolumn{5}{|c|}{ Anthropometric measurements } \\
\hline $\mathrm{SBP}(\mathrm{mmol} / \mathrm{l})$ & $130.3 \pm 1.8$ & $92-240$ & $129.1 \pm 2.0$ & $132.3 \pm 3.4$ \\
\hline $\mathrm{DBP}(\mathrm{mmol} / \mathrm{l})$ & $82.4 \pm 1.0$ & $60-140$ & $82.1 \pm 1.2$ & $83.1 \pm 1.6$ \\
\hline $\operatorname{BMI}\left(\mathrm{kg} / \mathrm{m}^{2}\right)$ & $23.8 \pm 0.2$ & $16.7-32.3$ & $24.3 \pm 0.3$ & $22.9 \pm 0.4^{\mathrm{b}}$ \\
\hline \multicolumn{5}{|l|}{ Blood lipids } \\
\hline FBG (mmol/l) & $7.0 \pm 0.3$ & $2.1-33.4$ & $6.9 \pm 0.3$ & $7.1 \pm 0.5$ \\
\hline $\mathrm{TG}(\mathrm{mmol} / \mathrm{l})$ & $1.8 \pm 0.1$ & $0.4-9.0$ & $1.7 \pm 0.1$ & $1.8 \pm 0.2$ \\
\hline $\mathrm{TC}(\mathrm{mmol} / \mathrm{l})$ & $4.7 \pm 0.1$ & $0.6-21.5$ & $4.6 \pm 0.2$ & $4.8 \pm 0.2$ \\
\hline HDL-C (mmol/l) & $1.4 \pm 0.1$ & $0.5-9.4$ & $1.4 \pm 0.1$ & $1.5 \pm 0.1$ \\
\hline LDL-C (mmol/l) & $2.4 \pm 0.1$ & $0.4-7.2$ & $2.4 \pm 0.1$ & $2.5 \pm 0.1$ \\
\hline \multicolumn{5}{|c|}{ Ultrasonic measurements } \\
\hline $\mathrm{IMR}(\mu \mathrm{m})$ & $72.0 \pm 3.6$ & 10.9-230.0 & $74.5 \pm 4.8$ & $68.1 \pm 5.7$ \\
\hline $\mathrm{IMT}_{\text {Mean }}(\mu \mathrm{m})$ & $675.3 \pm 12.8$ & $372.0-1354.2$ & $685.1 \pm 16.4$ & $660.4 \pm 20.5$ \\
\hline $\operatorname{IMT}_{\text {Max }}(\mu \mathrm{m})$ & $822.6 \pm 22.2$ & $430.6-2217.9$ & $843.7 \pm 28.5$ & $790.2 \pm 35.5$ \\
\hline $\mathrm{IMT}_{\text {Min }}(\mu \mathrm{m})$ & $565.0 \pm 9.9$ & 294.0-1018.4 & $573.9 \pm 13.4$ & $551.3 \pm 14.2$ \\
\hline Plaque & $57(30.8)$ & & $32(28.6)$ & $25(34.2)$ \\
\hline
\end{tabular}

${ }^{\mathrm{a}} \mathrm{P}<0.01$ (Chi-square test); ${ }^{\mathrm{b}} \mathrm{P}<0.01$ (t-test). Values are expressed as the mean \pm standard error of the mean or $\mathrm{n}(\%)$. SBP, systolic blood pressure; DBP, diastolic blood pressure; BMI, body mass index; FBG, fasting blood glucose; TG, triacylglycerol; TC, total cholesterol; HDL-C, high-density lipoprotein cholesterol; LDL-C, low-density lipoprotein cholesterol; IMR, intima-media roughness; IMT Mean/Max/Min $_{\text {, }}$ mean/maximum/minimum intima-media thickness.
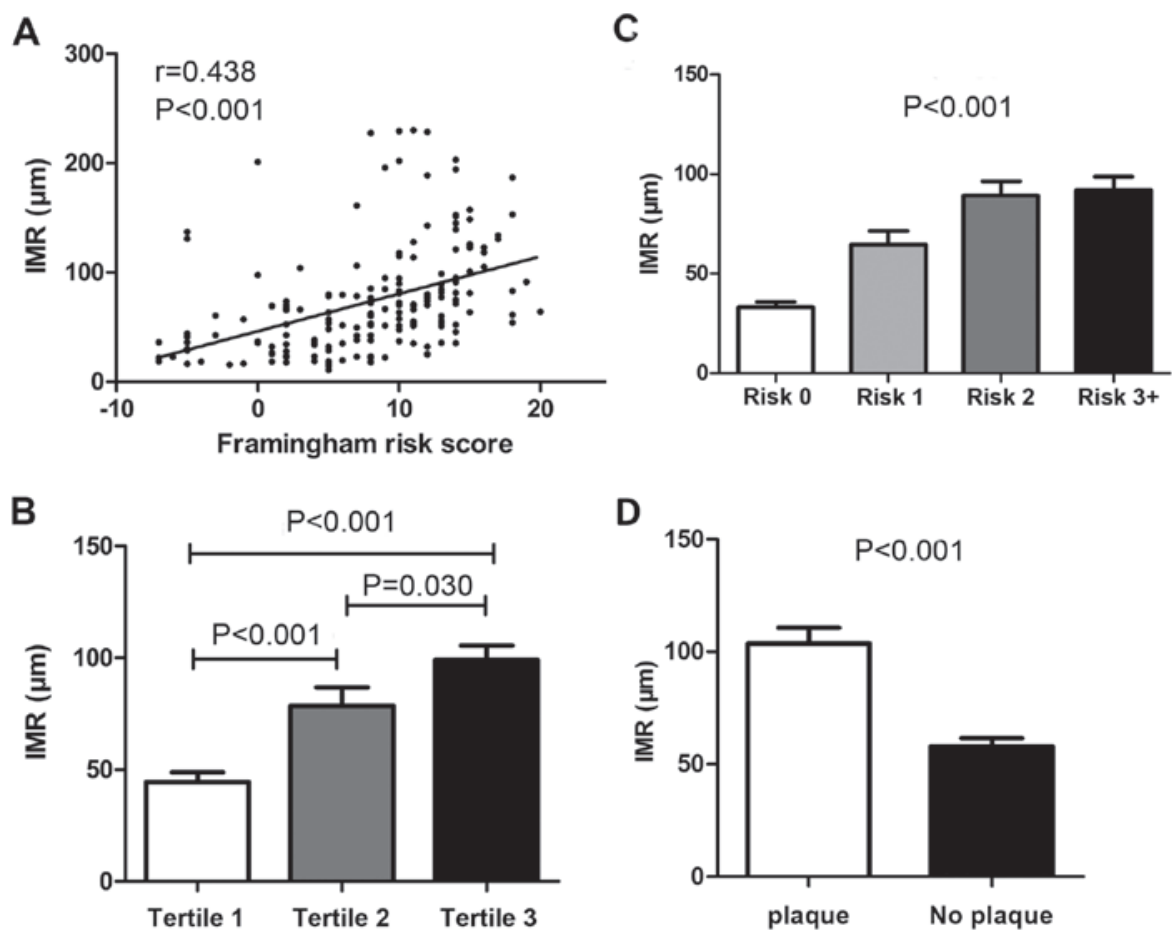

Figure 2. Correlation between IMR, IMT and cardiovascular risk factors. (A) Correlation between IMR and Framingham risk score. (B) IMR according to tertiles of cardiovascular risk factor score. (C) IMR according to numbers of cardiovascular risk factors. (D) IMR according to carotid plaques. IMT, intima-media thickness; IMR, intima-media roughness. 
Table II. Characteristics of subjects according to number of risk factors for coronary heart disease.

Number of risk factors

\begin{tabular}{|c|c|c|c|c|}
\hline \multirow[b]{2}{*}{ Parameter } & \\
\hline & 0 & 1 & 2 & $\geq 3$ \\
\hline Number of patients & 40 & 43 & 53 & 49 \\
\hline Age (years) & $39.6 \pm 1.5$ & $51.0 \pm 2.2^{\mathrm{a}}$ & $52.2 \pm 1.7^{\mathrm{a}}$ & $55.6 \pm 1.7^{\mathrm{a}}$ \\
\hline Males & $17(42.5)$ & $30(71.4)^{\mathrm{d}}$ & $31(58.5)^{\mathrm{d}}$ & $34(69.4)^{\mathrm{d}}$ \\
\hline SBP & $119.0 \pm 1.3$ & $120.9 \pm 1.5$ & $134.2 \pm 4.1^{\mathrm{a}, \mathrm{b}}$ & $144.3 \pm 4.1^{\mathrm{a}-\mathrm{c}}$ \\
\hline DBP & $78.5 \pm 1.0$ & $78.6 \pm 0.9$ & $85.1 \pm 2.3^{\mathrm{a}, \mathrm{b}}$ & $86.5 \pm 2.2^{\mathrm{a}, \mathrm{b}}$ \\
\hline BMI & $22.4 \pm 0.4$ & $24.1 \pm 0.4$ & $23.2 \pm 0.4$ & $25.1 \pm 0.5$ \\
\hline FBG & $5.2 \pm 0.1$ & $5.8 \pm 0.4$ & $7.5 \pm 0.7^{\mathrm{a}, \mathrm{b}}$ & $9.0 \pm 0.5^{\mathrm{a}-\mathrm{c}}$ \\
\hline $\mathrm{TG}$ & $1.1 \pm 0.1$ & $1.4 \pm 0.2$ & $1.9 \pm 0.2^{\mathrm{a}}$ & $2.4 \pm 0.2^{\mathrm{a}-\mathrm{c}}$ \\
\hline $\mathrm{TC}$ & $4.5 \pm 0.1$ & $4.6 \pm 0.2$ & $4.5 \pm 0.2$ & $5.0 \pm 0.4$ \\
\hline HDL & $1.7 \pm 0.1$ & $1.4 \pm 0.1$ & $1.3 \pm 0.1$ & $1.4 \pm 0.2$ \\
\hline LDL & $2.4 \pm 0.1$ & $2.5 \pm 0.1$ & $2.4 \pm 0.1$ & $2.6 \pm 0.2$ \\
\hline Smoking (\%) & $0(0)$ & $12(27.9)^{\mathrm{d}}$ & $18(34.0)^{\mathrm{d}}$ & $22(44.9)^{\mathrm{d}}$ \\
\hline IMR & $32.9 \pm 2.7$ & $64.5 \pm 6.9^{a}$ & $89.1 \pm 7.4^{\mathrm{a}, \mathrm{b}}$ & $92.0 \pm 6.7^{\mathrm{a}, \mathrm{b}}$ \\
\hline $\mathrm{IMT}_{\text {Mean }}$ & $551.4 \pm 19.9$ & $672.4 \pm 21.5^{\mathrm{a}}$ & $708.8 \pm 24.9^{a}$ & $742.9 \pm 25.3^{\mathrm{a}, \mathrm{b}}$ \\
\hline $\mathrm{IMT}_{\mathrm{Max}}$ & $637.3 \pm 30.4$ & $810.9 \pm 40.0^{\mathrm{a}}$ & $875.4 \pm 46.3^{\mathrm{a}}$ & $927.0 \pm 43.9^{\mathrm{a}, \mathrm{b}}$ \\
\hline $\mathrm{IMT}_{\mathrm{Min}}$ & $476.9 \pm 18.0$ & $580.8 \pm 17.2^{\mathrm{a}}$ & $594.3 \pm 18.9^{\mathrm{a}}$ & $591.2 \pm 19.6^{\mathrm{a}}$ \\
\hline Plaque (\%) & $2(5.0)$ & $7(16.3)$ & $24(45.3)^{\mathrm{d}, \mathrm{e}}$ & $24(49.0)^{\mathrm{d}, \mathrm{e}}$ \\
\hline
\end{tabular}

The following risk factors were considered: Age $\geq 55$ years, diabetes, dyslipidemia, obesity, current smoking and hypertension. ${ }^{\mathrm{a} P}<0.05 \mathrm{vs} .0$ risk factors; ${ }^{\mathrm{b}} \mathrm{P}<0.05$ vs. 1 risk factor; ${ }^{\mathrm{c}} \mathrm{P}<0.05$ vs. 2 risk factors (analysis of variance with least-significant differences test). ${ }^{\mathrm{d}} \mathrm{P}<0.05$ vs. 0 risk factors; ${ }^{\mathrm{e}} \mathrm{P}<0.05$ vs. 1 risk factor (Chi-square test). Values are expressed as the mean \pm standard error of the mean or $\mathrm{n}(\%)$. SBP, systolic blood pressure; DBP, diastolic blood pressure; BMI, body mass index; FBG, fasting blood glucose; TG, triacylglycerol; TC, total cholesterol; HDL-C, high-density lipoprotein cholesterol; LDL-C, low-density lipoprotein cholesterol; IMR, intima-media roughness; IMT ${ }_{\text {Mean/Max/Min }}$, mean/maximum/minimum intima-media thickness.

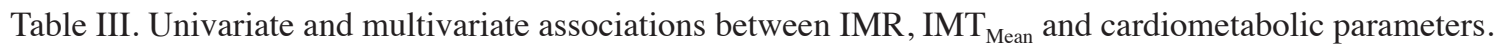

\begin{tabular}{|c|c|c|c|c|}
\hline \multirow[b]{2}{*}{ Parameter } & \multicolumn{2}{|c|}{ IMR } & \multicolumn{2}{|c|}{$\mathrm{IMT}_{\text {Mean }}$} \\
\hline & Univariate analysis & Multivariate analysis & Univariate analysis & Multivariate analysis \\
\hline Age & $0.361^{\mathrm{b}}$ & $0.292^{\mathrm{b}}$ & $0.447^{\mathrm{b}}$ & $0.376^{\mathrm{b}}$ \\
\hline SBP & $0.353^{\mathrm{b}}$ & $0.266^{\mathrm{b}}$ & $0.328^{\mathrm{b}}$ & $0.225^{\mathrm{b}}$ \\
\hline DBP & $0.255^{\mathrm{b}}$ & & $0.224^{\mathrm{b}}$ & \\
\hline Smoking & $0.263^{\mathrm{b}}$ & $0.289^{\mathrm{b}}$ & $0.207^{\mathrm{b}}$ & $0.191^{\mathrm{b}}$ \\
\hline FBG & 0.131 & & 0.102 & \\
\hline BMI & 0.142 & & $0.165^{\mathrm{a}}$ & \\
\hline $\mathrm{TC} / \mathrm{HDL}-\mathrm{C}$ ratio & $0.222^{\mathrm{b}}$ & $0.193^{\mathrm{b}}$ & $0.157^{\mathrm{b}}$ & $0.142^{\mathrm{b}}$ \\
\hline
\end{tabular}

${ }^{\mathrm{a}} \mathrm{P}<0.05 ;{ }^{\mathrm{b}} \mathrm{P}<0.01$. SBP, systolic blood pressure; DBP, diastolic blood pressure; BMI, body mass index; FBG, fasting blood glucose; TC, total cholesterol; HDL-C, high-density lipoprotein cholesterol; IMR, intima-media roughness; $\mathrm{IMT}_{\text {Mean }}$, mean intima-media thickness.

to atherosclerosis. Homma et al (7) indicated that increasing IMT at plaque-free sites does not indicate atherosclerotic changes and reflects diffuse physiologic aging processes as diffuse intimal thickening.

In the present study, IMR was significantly higher in subjects with carotid plaque than in subjects without carotid plaque. For cases with IMR $>84.8 \mu \mathrm{m}$, the prevalence of plaque in the carotid arteries is 11 times higher than in subjects with IMR $<33.8 \mu \mathrm{m}$ (cut-off values selected from IMR tertiles), adjusted for age, sex, smoking status, obesity, hypertension, diabetes mellitus and hyperlipidemia. This result demonstrates that IMR may be used as a novel indicator to evaluate the risk of atherosclerosis, which is consistent with the results of other studies. Graf et al (30) revealed that the 
Table IV. ORs for the influence of IMR in different tertiles on carotid atherosclerosis in all subjects.

\begin{tabular}{lcccccc}
\hline IMR & $\mathrm{n}$ & Plaque & Crude OR $(95 \% \mathrm{CI})$ & Crude P-value & Adjusted OR $(95 \% \mathrm{CI})$ & Adjusted P-value \\
\hline Tertile 1 & 61 & $3(4.9)$ & 1.00 & - & 1.00 & - \\
Tertile 2 & 62 & $21(33.9)^{\mathrm{a}}$ & $9.90(2.77-35.41)$ & $<0.001$ & $3.32(0.72-15.37)$ & 0.124 \\
Tertile 3 & 62 & $33(53.2)^{\mathrm{a}, \mathrm{b}}$ & $22.00(6.22-77.81)$ & $<0.001$ & $10.61(2.15-52.49)$ & 0.004 \\
\hline
\end{tabular}

Logistic regression adjusted for age, sex, smoking, obesity, hypertension, diabetes mellitus and hyperlipidemia. ${ }^{\text {a }} \mathrm{P}<0.01 \mathrm{vs}$. Tertile 1 ; ${ }^{\text {P }}<0.05$ vs. Tertile 2 (Chi-square test). Tertile 1 is the reference group. OR, odds ratio; IMR, intima-media roughness.

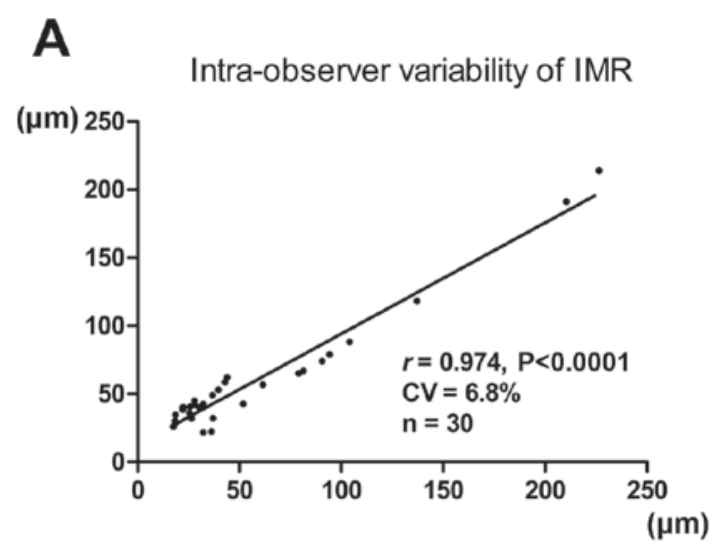

C Bland-Altman of IMR :Intra-observer

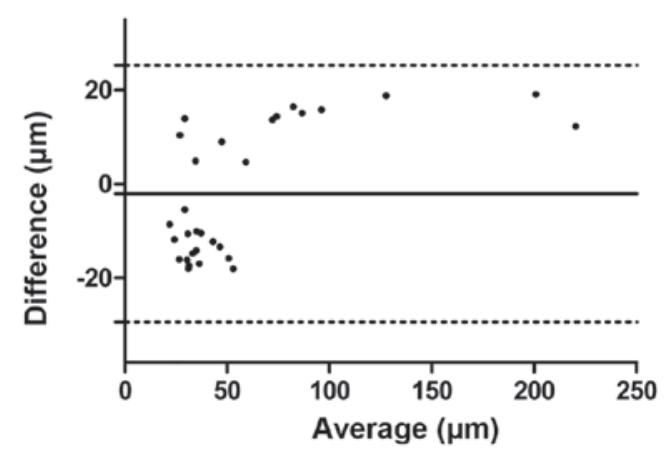

B

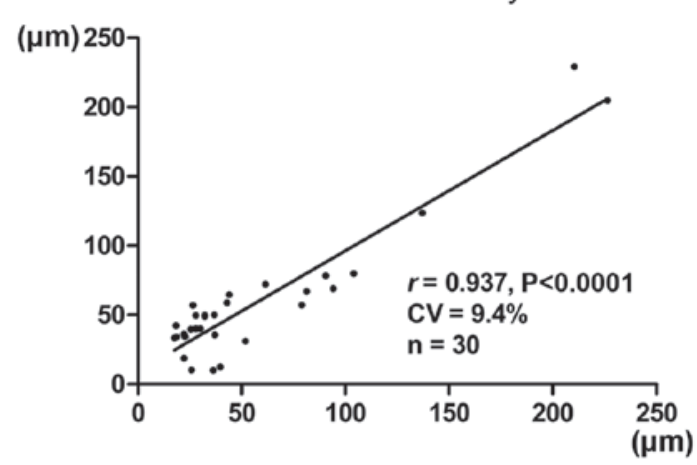

D Bland-Altman of IMR :Inter-observer

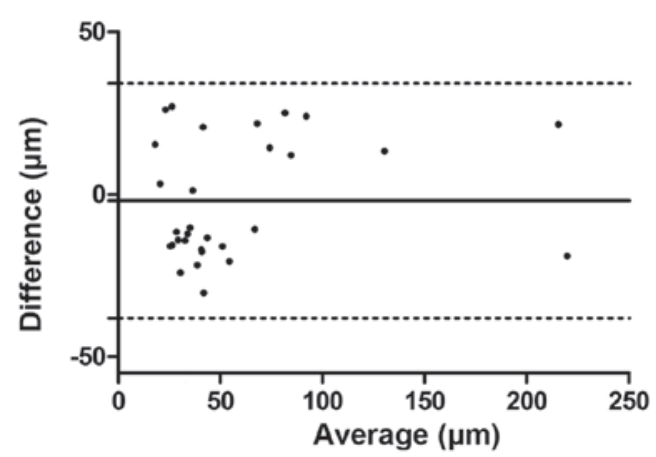

Figure 3. Intra-observer and inter-observer variability of IMR measurement. (A) Intra-observer variability of IMR measurement ( $\mathrm{n}=30, \mathrm{r}=0.974, \mathrm{CV}=6.8 \%$ ). (B) Inter-observer variability of IMR measurement $(n=30, r=0.937, C V=9.4 \%)$. (C and D) Bland-Altman plots indicating that differences between the two measurements were similar throughout the range of IMR. IMR, intima-media roughness; CV, coefficient of variation.

morphologic characteristics of the CCA (IMT inhomogeneity) are positively correlated with the degree of carotid bulb stenosis. Furthermore, as reported by Luijendijk et al (4) and Ishizu et al (31), the IMR of healthy subjects and patients with manifest coronary artery disease are significantly different. Belcaro et al (11) described these changes as granulations of the IM layer and developed a morphologic classification system of arterial wall changes. A 6-year follow-up was performed on 2,322 asymptomatic subjects, revealing that this structural alteration was a major criterion for future cardiovascular events. Therefore, it is necessary for subjects with IMR $\geq 84.8 \mu \mathrm{m}$ to be followed up closely, even if these subjects may not have combined carotid plaque and risk factors.

IMR has a potential application scope in future clinical practice: i) IMR may indicate atherosclerotic lesions prior to IM thickening, which may be the earliest morphological non-invasive index of atherosclerotic lesions that is detectable at present. ii) IMR as an indicator of cardiovascular risk may help to develop a clinical treatment strategy. iii) Due to the examination being non-invasive, simple and easy to repeat, IMR is a suitable parameter to effectively monitor the therapeutic effect of statins in carotid atherosclerotic lesions. With more studies supporting the diagnostic value of IMR, its clinical application prospects will be broader.

The present study had several limitations. Due to technical constraints, IMR and IMT were measured only at the straight artery, while the curved vascular segments and the plaques were avoided. Thus, the region of interest selected may not have been that with the most severe atherosclerosis. Furthermore, IMR and IMT require measurement with post-processing software following storage of the US 
image. Furthermore, the quality of the US image may affect the measurement with this analysis software. As another limitation, intracranial arteries cannot be examined using IMR scans. In addition, prospective studies are required to demonstrate the predictive effect of IMR regarding the risk of cardiovascular events.

In conclusion, IMR measurement of the CCA quantified in US images based on this computer-assisted analysis software is feasible. Carotid IMR, which reflects the morphological changes of the IM layer, may help estimate the extent of atherosclerosis and may be used for risk stratification of patients with cardiovascular risk factors.

\section{Acknowledgements}

Not applicable.

\section{Funding}

The present study was supported by the National Natural Science Foundation of China (grant nos. 81601540, 81500109, 81530056, 81671705 and 81401429), Huazhong University of Science and Technology Interdisciplinary Innovation Team (grant no. 0118530300) and the Fundamental Research Funds for the Central Universities, HUST (grant nos. 2015LC024 and 2015QN208).

\section{Availability of data and materials}

The datasets used and/or analyzed during the present study are available from the corresponding author on reasonable request.

\section{Authors' contributions}

QL and XYC designed the study. YW, QL, XL and LY performed data acquisition, analysis, interpretation of the data and drafting of the manuscript. YW and XL carried out statistical analysis. YW, XL, LZ, LY, MXX and QL acquired funding. QL, MXX supervised the study. YW and XYC analyzed data using various software applications. YW, XL, QL, MXX, LZ, QL checked the integrity of the data and accuracy of the data analysis. All authors read and approved the final manuscript.

\section{Ethics approval and consent to participate}

The present study was approved by the Ethics Committee of the Union Hospital at Huazhong University of Science and Technology (Wuhan, China), and the methods were applied in accordance with the approved guidelines. Informed consent was obtained from all patients.

\section{Patient consent for publication}

Not applicable.

\section{Competing interests}

The authors declare that they have no competing interests.

\section{References}

1. He J, Gu D, Wu X, Reynolds K, Duan X, Yao C, Wang J, Chen CS, Chen J, Wildman RP, et al: Major causes of death among men and women in China. N Engl J Med 353: 1124-1134, 2005.

2. Touboul PJ, Labreuche J, Bruckert E, Schargrodsky H, Prati P, Tosetto A, Hernandez-Hernandez R, Woo KS, Silva H, Vicaut E and Amarenco P: Hdl-c, triglycerides and carotid IMT: A meta-analysis of 21,000 patients with automated edge detection IMT measurement. Atherosclerosis 232: 65-71, 2014.

3. Lethen H, Tries HP, Kersting S, Bramlage P and Lambertz H: Improvement of coronary microvascular function after angiotensin receptor blocker treatment with irbesartan in patients with systemic hypertension. J Clin Hypertens (Greenwich) 13: 155-161, 2011.

4. Luijendijk P, Lu H, Heynneman FB, Huijgen R, de Groot EE, Vriend JW, Vliegen HW, Groenink M, Bouma BJ and Mulder BJ: Increased carotid intima-media thickness predicts cardiovascular events in aortic coarctation. Int J Cardiol 176: 776-781, 2014.

5. Schmidt-Trucksass A, Sandrock M, Cheng DC, Müller HM, Baumstark MW, Rauramaa R, Berg A and Huonker M: Quantitative measurement of carotid intima-media roughness-effect of age and manifest coronary artery disease. Atherosclerosis 166: 57-65, 2003.

6. Dalla Pozza R, Pirzer R, Beyerlein A, Weberruß H, Oberhoffer R, Schmidt-Trucksäss A, Netz H and Haas N: Beyond intima-media-thickness: Analysis of the carotid intima-media-roughness in a paediatric population. Atherosclerosis 251: 164-169, 2016.

7. Homma S, Hirose N, Ishida H, Ishii T and Araki G: Carotid plaque and intima-media thickness assessed by b-mode ultrasonography in subjects ranging from young adults to centenarians. Stroke 32: 830-835, 2001 .

8. Lind L: Circulating markers of inflammation and atherosclerosis. Atherosclerosis 169: 203-214, 2003.

9. Willerson JT: Systemic and local inflammation in patients with unstable atherosclerotic plaques. Prog Cardiovasc Dis 44: 469-478, 2002.

10. Toutouzas K, Grassos H, Synetos A, Drakopoulou M, Tsiamis E, Moldovan C, Agrogiannis G, Patsouris E, Siores E and Stefanadis C: A new non-invasive method for detection of local inflammation in atherosclerotic plaques: Experimental application of microwave radiometry. Atherosclerosis 215: 82-89, 2011.

11. Belcaro G, Nicolaides AN, Laurora G, Cesarone MR, De Sanctis M, Incandela L and Barsotti A: Ultrasound morphology classification of the arterial wall and cardiovascular events in a 6-year follow-up study. Arterioscler Thromb Vasc Biol 16: 851-856, 1996.

12. Mancia G, Fagard R, Narkiewicz K, Redón J, Zanchetti A, Böhm M, Christiaens T, Cifkova R, De Backer G, Dominiczak A, et al: 2013 ESH/ESC guidelines for the management of arterial hypertension: The task force for the management of arterial hypertension of the european society of hypertension (ESH) and of the european society of cardiology (ESC). J Hypertens 31: 1281-1357, 2013.

13. Gnasso A, Irace C, Mattioli PL and Pujia A: Carotid intima-media thickness and coronary heart disease risk factors. Atherosclerosis 119: 7-15, 1996.

14. American Diabetes Association: Standards of medical care in diabetes-2011. Diabetes Care 1 (Suppl 34): S11-S61, 2011.

15. Zhou B; Coorperative Meta-Analysis Group Of China Obesity Task Force: Predictive values of body mass index and waist circumference to risk factors of related diseases in Chinese adult population. Zhonghua Liu Xing Bing Xue Za Zhi 23: 5-10, 2002 (In Chinese).

16. Expert Panel on Detection and Evaluation and Treatment of High Blood Cholesterol in Adults: Executive summary of the third report of the national cholesterol education program (NCEP) expert panel on detection, evaluation, and treatment of high blood cholesterol in adults (Adult Treatment Panel III). JAMA 285: 2486-2497, 2001.

17. Touboul PJ, Hennerici M, Meairs S, Adams H, Amarenco P, Bornstein N, Csiba L, Desvarieux M, Ebrahim S, Hernandez Hernandez R, et al: Mannheim carotid intima-media thickness and plaque consensus (2004-2006-2011). An update on behalf of the advisory board of the 3rd, 4th and 5th watching the risk symposia, at the 13th, 15th and 20th European stroke conferences, mannheim, Germany, 2004, Brussels, Belgium, 2006, and hamburg, Germany, 2011. Cerebrovasc Dis 34: 290-296, 2012. 
18. Xu X, Zhou Y, Cheng X, Song E and Li G: Ultrasound intima-media segmentation using hough transform and dual snake model. Comput Med Imaging Graph 36: 248-258, 2012.

19. Wendelhag I, Gustavsson T, Suurküla M, Berglund G and Wikstrand J: Ultrasound measurement of wall thickness in the carotid artery: Fundamental principles and description of a computerized analysing system. Clin Physiol 11: 565-577, 1991.

20. Oh J, Wunsch R, Turzer M, Bahner M, Raggi P, Querfeld U, Mehls $\mathrm{O}$ and Schaefer F: Advanced coronary and carotid arteriopathy in young adults with childhood-onset chronic renal failure. Circulation 106: 100-105, 2002.

21. Polak JF, Pencina MJ, Pencina KM, O'Donnell CJ, Wolf PA and D'Agostino RB Sr: Carotid-wall intima-media thickness and cardiovascular events. N Engl J Med 365: 213-221, 2011.

22. Gardin JM, Bartz TM, Polak JF, O'Leary DH and Wong ND: What do carotid intima-media thickness and plaque add to the prediction of stroke and cardiovascular disease risk in older adults? The cardiovascular health study. J Am Soc Echocardiogr 27: 998-1005, 2014.

23. Polak JF, Szklo M and O'Leary DH: Associations of coronary heart disease with common carotid artery near and far wall intima-media thickness: The Multi-Ethnic Study of Atherosclerosis. J Am Soc Echocardiogr 28: 1114-1121, 2015.

24. Gigante B, Leander K, Vikström M, Baldassarre D, Veglia F, Strawbridge RJ, McLeod O, Gertow K, Sennblad B, Shah S, et al: Low levels of $\operatorname{IgM}$ antibodies against phosphorylcholine are associated with fast carotid intima media thickness progression and cardiovascular risk in men. Atherosclerosis 236: 394-399, 2014.

25. Wu Y, Xie M, Zhang L, Lu X, Cheng X and Lv Q: Carotid intima-media roughness and elasticity in hypertensive patients with normal carotid intima-media thickness. J Ultrasound Med, 2018 (Epub ahead of print).
26. Raitakari OT, Juonala M, Kähönen $M$, Taittonen L, Laitinen T, Mäki-Torkko N, Järvisalo MJ, Uhari M, Jokinen E, Rönnemaa T, et al: Cardiovascular risk factors in childhood and carotid artery intima-media thickness in adulthood: The Cardiovascular Risk in Young Finns Study. JAMA 290: 2277-2283, 2003.

27. Cheng $X$, Zhou Y, Jin Y, Li G, Wang H and Song E: Intima-medial thickness homogeneity in the common carotid artery: Measurement method and preliminary clinical study. J Clin Ultrasound 40: 559-565, 2012.

28. Otsuka F, Kramer MC, Woudstra P, Yahagi K, Ladich E, Finn AV, de Winter RJ, Kolodgie FD, Wight TN, Davis HR, et al: Natural progression of atherosclerosis from pathologic intimal thickening to late fibroatheroma in human coronary arteries: A pathology study. Atherosclerosis 241: 772-782, 2015.

29. Bentzon JF, Otsuka F, Virmani R and Falk E: Mechanisms of plaque formation and rupture. Circ Res 114: 1852-1866, 2014.

30. Graf IM, Schreuder FH, Hameleers JM, Mess WH, Reneman RS and Hoeks AP: Wall irregularity rather than intima-media thickness is associated with nearby atherosclerosis. Ultrasound Med Biol 35: 955-961, 2009.

31. Ishizu T, Ishimitsu T, Kamiya H, Seo Y, Moriyama N, Obara K, Watanabe $\mathrm{S}$ and Yamaguchi I: The correlation of irregularities in carotid arterial intima-media thickness with coronary artery disease. Heart Vessels 17: 1-6, 2002. International (CC BY-NC-ND 4.0) License. 